\title{
BMJ Open Long-term effectiveness of the community-based Complete Health Improvement Program (CHIP) lifestyle intervention: a cohort study
}

\author{
Lillian Kent, ${ }^{1}$ Darren Morton, ${ }^{1}$ Trevor Hurlow, ${ }^{2}$ Paul Rankin, ${ }^{1}$ Althea Hanna, ${ }^{3}$ \\ Hans Diehl ${ }^{4}$
}

To cite: Kent $L$, Morton $D$, Hurlow $\mathrm{T}$, et al. Long-term effectiveness of the community-based Complete Health Improvement Program (CHIP) lifestyle intervention: a cohort study. BMJ Open 2013;3:e003751.

doi:10.1136/bmjopen-2013003751

- Prepublication history for this paper is available online. To view these files please visit the journal online (http://dx.doi.org/10.1136/ bmjopen-2013-003751).

Received 7 August 2013 Revised 14 October 2013 Accepted 21 October 2013

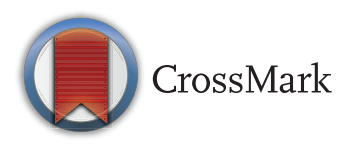

${ }^{1}$ Lifestyle Research Centre, Avondale College of Higher Education, Cooranbong, New South Wales, Australia ${ }^{2}$ Waratah Medical Services, Morisset, New South Wales, Australia

${ }^{3}$ Department of Health, New Zealand Pacific Union

Conference, Auckland, New Zealand

${ }^{4}$ Lifestyle Medicine Institute, Loma Linda, California, USA

Correspondence to Dr Lillian Kent;

lillian.kent@avondale.edu.au

\section{ABSTRACT}

Objective: To examine the long-term (three or more years) effectiveness of the volunteer-delivered Complete Health Improvement Program (CHIP) intervention.

Design: Cohort study.

Setting: Hawera, New Zealand.

Participants: Of the total cohort of 284 individuals who self-selected to complete the CHIP lifestyle intervention between 2007 and 2009, 106 (37\% of the original cohort, mean age $=64.9 \pm 7.4$ years, range 42 87 years; $35 \%$ males, $65 \%$ female) returned in 2012 for a complimentary follow-up health assessment (mean follow-up duration=49.2+10.4 months).

Intervention: 30-day lifestyle modification programme (diet, physical activity, substance use and stress management) delivered by volunteers in a community setting.

Main outcome measures: Changes in body mass index (BMI), systolic blood pressure (SBP) and diastolic blood pressure (DBP), fasting plasma glucose (FPG), total cholesterol (TC), low-density lipoprotein (LDL), high-density lipoprotein (HDL) and triglycerides (TG).

Results: After approximately 4 years, participants with elevated biometrics at programme entry maintained significantly lowered BMI $(-3.2 \% ; 34.8 \pm 5.4$ vs $\left.33.7 \pm 5.3 \mathrm{~kg} / \mathrm{m}^{2}, \mathrm{p}=0.02\right)$, DBP $(-9.4 \% ; 89.1 \pm 4.1 \mathrm{vs}$ $80.8 \pm 12.6 \mathrm{~mm} \mathrm{Hg}, p=0.005)$, TC $(-5.5 \% ; 6.1 \pm 0.7$ vs $5.8 \pm 1.0 \mathrm{mmol} / \mathrm{L}, p=0.04)$ and $\mathrm{TG}(-27.5 \% ; 2.4 \pm 0.8 \mathrm{vs}$ $1.7 \pm 0.7 \mathrm{mmol} / \mathrm{L}, \mathrm{p}=0.002)$. SBP, $\mathrm{HDL}, \mathrm{LDL}$ and FPG were not significantly different from baseline. Participants with elevated baseline biometrics who reported being compliant to the lifestyle principles promoted in the intervention ( $\mathrm{N}=71,67 \%$ of follow-up participants) recorded further reductions in BMI $\left(-4.2 \% ; 34.8 \pm 4.5\right.$ vs $33.4 \pm 4.8 \mathrm{~kg} / \mathrm{m}^{2}$, $\mathrm{p}=0.02)$, DBP $(-13.3 \% ; 88.3 \pm 3.2$ vs $77.1 \pm 12.1 \mathrm{~mm} \mathrm{Hg}$, $\mathrm{p}=0.005)$ and $\mathrm{FPG}(-10.4 \% ; 7.0 \pm 1.5$ vs $6.3 \pm 1.3 \mathrm{mmol} / \mathrm{L}$, $\mathrm{p}=0.02$ ).

Conclusions: Individuals who returned for follow-up assessment and entered the CHIP lifestyle intervention with elevated risk factors were able to maintain improvements in most biometrics for more than 3 years. The results suggest that the community-based CHIP lifestyle intervention can be effective in the longer term, even when delivered by volunteers.

\section{Strengths and limitations of this study}

- Long-term appraisal of a lifestyle intervention programme.

- This study compares favourably with other professionally delivered non-Complete Health Improvement Program (CHIP) lifestyle interventions, for example, Diabetes Prevention Program.

- Small sample size.

- Possible selection bias in the follow-up group with $37 \%$ returning for long-term follow-up.

- Compliance to lifestyle behaviours was inadequately measured.

\section{INTRODUCTION}

The burden of chronic diseases, including cardiovascular disease, diabetes and cancer, represents a major health challenge worldwide. ${ }^{1} 2$ Deaths from chronic diseases are projected to increase by $15 \%$ by $2020 .{ }^{1}$ Unhealthy lifestyle is recognised as one of the major risk factors of chronic diseases ${ }^{1}$ and lifestyle interventions have been shown to be efficacious for their primary, secondary and early tertiary prevention. ${ }^{3-8}$ Consequentially, lifestyle interventions are attracting increasing attention for managing the burgeoning rise of chronic disease.

While the merits of lifestyle interventions for managing chronic diseases are acknowledged, concerns exist regarding recidivism and cost. Health behaviour decay is commonly observed in weight loss interventions, with long-term adherence to dietary modifications typically only achieved by a small proportion of individuals. ${ }^{9}{ }^{10}$ Notwithstanding, the Diabetes Prevention Program has shown meaningful reductions in body mass for up to 10 years after programme entry. ${ }^{11}$ With regard to cost, lifestyle interventions are often resource intensive and hence expensive. Residential programmes, while demonstrating a high level of efficacy in the short 
term, are especially cost prohibitive for many individuals. However, an increasing number of community-based interventions are becoming available. Recently, an adaptation of the Diabetes Prevention Program, utilising community health workers in community settings, was shown to be effective in reducing and maintaining reductions in weight, waist circumference and various diabetes indices 2 years after programme entry. ${ }^{12}$

The Complete Health Improvement Program (CHIP) is an intensive, community-based lifestyle intervention that has demonstrated significant short-term benefits for the management of a number of chronic diseases. ${ }^{13-16}$ The CHIP intervention has been delivered by both health professionals ${ }^{1718}$ and trained volunteers. ${ }^{78}$ The aim of this study was to examine the long-term effectiveness of volunteer-delivered CHIP interventions which can be facilitated inexpensively.

\section{METHODS}

The study targeted a rural community in New Zealand where 30-day CHIP interventions have been delivered by a team of volunteers since 2007. The volunteers had undergone 2 days of training to develop group facilitation skills and then been equipped with the comprehensive CHIP resource package that included: a curriculum guide for programme delivery, 16 prerecorded educational lectures presented by qualified experts, a cookbook and participant textbook and journal. The role of the volunteer director was to organise and facilitate the proceedings of the group sessions, not to educate.

All 323 individuals, who had previously completed the CHIP intervention, were invited, by letter, to participate in a follow-up study, irrespective of their outcomes at 30 days. The letter included information detailing the intent of the study, as well as a complementary follow-up medical assessment and a form for the participant to provide informed consent. Though the purpose of the study was to look at the long-term effects of the programme (3+years) it was considered ethical to offer a follow-up health check to all the participants. Of the 192 that replied (59\% response rate), 142 consented to participate; 50 did not. On the designated day for the study, 130 returned for the follow-up assessment. Of these 130 individuals, 106 (age $=64.9 \pm 7.4$ years, range $42-87$ years) who had completed the intervention 3 or more years previously (mean $=49.2 \pm 10.4$ months, range $=3-5$ years $)$ were included in this study. As 284 of the original cohort of 323 participants had completed the intervention 3 or more years previously, the response rate for this study was $37 \%$.

The 30-day group-based CHIP intervention, previously described, ${ }^{78}$ had encouraged and supported the participants to move towards a low-fat, plant-based diet ad libitum, with emphasis on the whole-foods consumption of grains, legumes, fruits and vegetables. The programme had also encouraged participants to engage in $30 \mathrm{~min}$ of moderate-intensity physical activity daily and practice stress management techniques. Following completion of the programme, a monthly support group was offered to the participants to reinforce lifestyle behavioural changes, and build a network of support and ongoing education, although it was not considered part of the intervention. The follow-up study was not planned at the time the participants enrolled in their respective CHIPs and so participants were not advised of this eventuality. Invitations were extended to all participants to attend the follow-up study, regardless of whether or not they chose to attend the monthly support meetings. The same team of volunteer facilitators had delivered all the CHIP interventions in a uniform manner, utilising the programme resources provided.

At programme entry, 30 days and follow-up (approximately 4 years), the participants' height, weight and blood pressure (BP) were taken by registered nurses, and fasting $(12 \mathrm{~h})$ blood samples were collected by trained phlebotomists and analysed by a local pathology laboratory. Blood samples were analysed for total cholesterol (TC), low-density lipoprotein (LDL), high-density lipoprotein (HDL), triglycerides (TG) and fasting plasma glucose (FPG) levels. At follow-up, participants were also asked to complete a questionnaire that assessed their compliance with lifestyle principles advocated by the CHIP intervention. Participants were also asked about their attendance at the postintervention monthly support meetings.

The data were analysed using IBM Statistics (V.19) and expressed as mean $\pm \mathrm{SD}$. The extent of changes (per cent and mean with $95 \%$ CIs) from baseline to postintervention (30 days) and follow-up (mean=49 months) were assessed using analysis of variance (repeated measures). We have previously shown that participants who make the greatest improvements in their biometrics during the CHIP intervention are those with the highest baseline levels. ${ }^{7}$ Hence, the participants were stratified by normal or elevated baseline biometric levels. Cut-points for the biometrics included in the metabolic syndrome assemblage, as described by Alberti et $a l^{19}$ were used: raised BP (systolic blood pressure (SBP) $\geq 130 \mathrm{~mm} \mathrm{Hg}$ and/or diastolic blood pressure (DBP) $\geq 85 \mathrm{~mm} \mathrm{Hg}$ ), elevated FPG $(\geq 5.5 \mathrm{mmol} / \mathrm{L})$, increased TG $(\geq 1.7 \mathrm{mmol} / \mathrm{L})$, decreased HDL $\quad(<1.03 \mathrm{mmol} / \mathrm{L}$ in men and $<1.3 \mathrm{mmol} / \mathrm{L}$ in women) and waist circumference indicative of central obesity. As waist circumference was not measured in this study, body mass index (BMI) $>30 \mathrm{~kg} / \mathrm{m}^{2}$ was used as a surrogate, as suggested by the International Diabetes Federation (IDF, 2006). Cut-points for TC $(\geq 5.2 \mathrm{mmol} / \mathrm{L})$ and LDL $(\geq 2.6 \mathrm{mmol} / \mathrm{L})$, not part of the suite of metabolic syndrome risk factors, were taken from the National Cholesterol Education Program Adult Treatment Panel III guidelines. ${ }^{20}$ Pearson's $\chi^{2}$ test was used on all demographic data variables, in order to investigate trends between participants who returned for follow-up and those who did not. Independent $\mathrm{t}$ tests were used to compare baseline biometrics. The relationships between nominal variables likely to be associated with CHIP compliance were 
examined using Spearman's rank-order correlation $(\rho)$ with two-tailed tests of significance. Participants were asked to what extent they adopted the principles promoted in the CHIP intervention since completing the programme and a dichotomous variable was created: compliant ('all' or 'most of principles') and non-compliant ('a few' or 'none of principles'). For all analyses, results were considered significant at $\mathrm{p}<0.05$.

\section{RESULTS}

Significant improvements in all biometrics were observed over the 30-day intervention for 106 participants who returned for the follow-up assessment (table 1), which is consistent with other studies of the 30-day effectiveness of the CHIP intervention. ${ }^{78}$ However, the primary interest of this study was the longer term sustainability. All biometrics significantly increased from programme completion to follow-up (table 1). However, weight was the only biometric in which a net improvement was sustained in the long term. Participants were able to maintain an average $1.6 \%$ decrease in body weight over the long term compared to their weight at programme entry. On the other hand, following programme completion, SBP increased resulting in a net $4.2 \%$ increase from baseline to follow-up.

There were no significant differences between the participants who did and did not undergo the 3-year to 5 -year follow-up testing in baseline age $(60.6$ vs 58.4 years, $\mathrm{p}=0.07)$, gender $(35.2 \%$ vs $34.6 \%$ men, $\mathrm{p}=0.92)$, marital status $(90 \%$ vs $80 \%$ married, $\mathrm{p}=0.18)$ and smoking status $(70.3 \%$ vs $68.8 \%, \mathrm{p}=0.28)$. Table 1 also shows baseline characteristics of participants who did and did not attend the 3-year to 5-year follow-up testing. There were no significant differences between the participants who did and did not undergo follow-up testing in SBP, DBP, TC, LDL and HDL. Individuals who did not attend the follow-up had significantly higher BMI, TG and FPG at programme entry. There were also no significant differences between those who did and who did not attend follow-up in 30-day levels of SBP, DBP, TC, LDL and FPG (table 1). However, there were no significant differences in the amount of change experienced in any of the biometrics during the 30-day intervention, even for the biometrics that were different between the groups at baseline.

For all 106 individuals who attended the follow-up, no significant change in any biometrics was found. However, when changes in the biometrics were examined by baseline level of risk, significant decreases in several biometrics were observed (table 2). Participants with elevated BMI, DBP, TC and TG at programme entry had significantly lowered levels of these biometrics at the 49-month follow-up (table 2). Conversely, follow-up levels of BP, LDL and FPG increased above baseline levels for participants who started the programme with normal levels (table 2).
Of the 106 CHIP participants who returned for follow-up assessments $71(67 \%)$ reported being compliant to the lifestyle principles following completion of the 30-day programme. However, no compliance information was recorded for the original cohort who did not attend the follow-up assessment. Participants who reported being compliant were $2.8 \pm 5.8 \mathrm{~kg}$ (95\% CI -4.48 to $-1.11 ; \mathrm{p}<0.001)$ lighter at follow-up compared to programme entry whereas the non-compliant participants had gained $1.8 \pm 7.0 \mathrm{~kg}(95 \% \mathrm{CI}-1.27$ to 4.82 ; $\mathrm{p}=0.46)$, amounting to a change difference of almost $5 \mathrm{~kg}$ between the groups $(\mathrm{p}=0.001)$. The compliant and non-compliant groups were further analysed according to baseline biometric risk levels (table 3). Similar trends can be observed in tables 2 and 3; however, compliant individuals who entered the programme at elevated risk had even greater improvements in BMI, DBP and FPG (table 3). Notably, compliant participants with elevated BMI at programme entry weighed $4.9 \pm 7.2 \mathrm{~kg}(95 \% \mathrm{CI}$ -8.10 to 1.62$)$ less at $3-5$ years of follow-up $(p=0.002)$. Compliant participants with elevated baseline biometrics had significant reductions at follow-up for 3 of the 5 criteria for the metabolic syndrome. Conversely, compliant participants who started the programme with normal baseline levels reported increases at follow-up in several biometrics (table 3). Analyses of the non-compliant participants by baseline risk levels were not possible due to small numbers.

Postintervention compliance was positively correlated with attendance at the monthly support meetings $(\rho=0.402, p<0.001)$. Although only 26 of the study participants reported attending these meetings, all of these individuals reported being compliant to the lifestyle principles presented in the programme. These individuals had a $3.5 \pm 4.8 \mathrm{~kg}(95 \% \mathrm{CI}-5.95$ to $-1.12 ; \mathrm{p}=0.003)$ weight loss at follow-up but this was not significantly different $(p=0.50)$ to the compliant individuals who did not attend the monthly support meetings $(2.6 \pm 6.2 \mathrm{~kg}$, $95 \%$ CI -4.92 to $-0.24 ; \mathrm{p}=0.03)$. While only few in number $(\mathrm{N}=13)$, participants who attended the support meetings and entered the programme with elevated BMI had a highly significant weight loss at follow-up (5.6 $\pm 5.3 \mathrm{~kg}, 95 \%$ CI -9.71 to $-1.46 ; \mathrm{p}=0.008)$. Yet this was once again not significantly different $(p=0.82)$ to the compliant individuals who entered the programme with elevated BMI but did not attend the support meetings $(\mathrm{N}=18 ; 5.0 \pm 8.2 \mathrm{~kg}, 95 \% \mathrm{CI}-10.11$ to $0.11 ; \mathrm{p}=0.06)$.

Attendance at monthly support meetings was not related to participating in the CHIP intervention with a spouse or friend $(\rho=0.008, p=0.93)$ : equal proportions of participants who attended with a partner either did or did not attend support meetings $(69.2 \%$ vs $68.4 \%$, $\mathrm{p}=0.93$ ). Similarly, attending the CHIP intervention with a partner was not related to reported compliance at follow-up $(\rho=0.17, p=0.08)$ : there was no difference in the proportion of individuals who participated with a partner who reported being compliant or not compliant $(73.2 \%$ vs $55.9 \%, \mathrm{p}=0.08)$. 
Table 1 Baseline biometrics and changes from baseline for participants who attended long-term follow-up ( $n=106)$ and those who did not $(n=178)$

\begin{tabular}{|c|c|c|c|c|c|c|c|c|c|}
\hline Biometric & $\begin{array}{l}\text { Attendance at } \\
\text { follow-up }\end{array}$ & $\mathbf{N}$ & Baseline & 30 days & $\begin{array}{l}\text { Mean change } 30 \text { days } \\
(95 \% \mathrm{Cl})\end{array}$ & $\begin{array}{l}\text { Per cent } \\
\text { change }\end{array}$ & $\begin{array}{l}3-5 \text { years of } \\
\text { follow-up }\end{array}$ & $\begin{array}{l}\text { Mean change } 3- \\
5 \text { years }(95 \% \mathrm{Cl})\end{array}$ & $\begin{array}{l}\text { Per cent } \\
\text { change† }\end{array}$ \\
\hline \multirow[t]{2}{*}{ Weight (kg) } & Attended & 106 & $83.42 \pm 17.05$ & $79.63 \pm 15.93$ & $-3.79(-4.20$ to -3.38$)$ & $-4.5^{\star *}$ & $82.12 \pm 16.17$ & $-1.30(-2.84$ to 0.24$)$ & $-1.6^{\star}$ \\
\hline & Did not attend & 178 & $91.14 \pm 19.1 \ddagger$ & $87.36 \pm 18.18 \S$ & $-3.78 \rrbracket(-4.12$ to -3.44$)$ & $-4.1^{\star *}$ & & & \\
\hline \multirow[t]{2}{*}{ BMI $\left(\mathrm{kg} / \mathrm{m}^{2}\right)$} & Attended & 106 & $30.07 \pm 5.57$ & $28.72 \pm 5.28$ & $-1.35(-1.49$ to -1.21$)$ & $-4.5^{\star \star}$ & $29.78 \pm 5.24$ & $-0.29(-0.84$ to 0.25$)$ & -1.0 \\
\hline & Did not attend & 178 & $32.92 \pm 6.56 \dagger \dagger$ & $31.57 \pm 6.30 \S$ & $-1.35 \rrbracket(-1.47$ to -1.24$)$ & $-4.1^{\star \star}$ & & & \\
\hline \multirow[t]{2}{*}{ SBP $(\mathrm{mm} \mathrm{Hg})$} & Attended & 106 & $130.32 \pm 13.05$ & $123.00 \pm 11.42$ & $-7.32(-9.48$ to -5.17$)$ & $-5.6^{\star \star}$ & $135.82 \pm 14.98$ & 5.50 (1.95 to 9.05$)$ & $4.2^{\star \star}$ \\
\hline & Did not attend & 178 & $132.92 \pm 15.55$ & $125.98 \pm 13.88$ & $-6.94 \rrbracket(-9.82$ to -5.05$)$ & $-5.2^{\star \star}$ & & & \\
\hline \multirow[t]{2}{*}{ DBP $(\mathrm{mm} \mathrm{Hg})$} & Attended & 106 & $76.92 \pm 10.30$ & $73.41 \pm 10.47$ & $-3.51(-5.46$ to -1.56$)$ & $-4.6^{\star}$ & $78.40 \pm 11.60$ & $1.48(-0.79$ to 3.76$)$ & 1.9 \\
\hline & Did not attend & 178 & $77.36 \pm 11.34$ & $73.04 \pm 10.45$ & $-4.32 \rrbracket(-5.81$ to -2.83$)$ & $-5.6^{\star *}$ & & & \\
\hline \multirow[t]{2}{*}{$\mathrm{TC}(\mathrm{mmol} / \mathrm{L})$} & Attended & 106 & $5.35 \pm 1.04$ & $4.33 \pm 0.99$ & $-1.01(-1.13$ to -0.90$)$ & $-18.9^{\star \star}$ & $5.31 \pm 1.19$ & $-0.04(-0.29$ to 0.21$)$ & -0.7 \\
\hline & Did not attend & 178 & $5.27 \pm 1.11$ & $4.31 \pm 1.01$ & $-0.96 \rrbracket(-1.05$ to -0.86$)$ & $-18.2^{\star \star}$ & & & \\
\hline \multirow[t]{2}{*}{$\mathrm{HDL}(\mathrm{mmol} / \mathrm{L})$} & Attended & 106 & $1.35 \pm 0.32$ & $1.23 \pm 0.28$ & $-0.12(-0.15$ to -0.09$)$ & $-8.7^{\star \star}$ & $1.31 \pm 0.33$ & $-0.04(-0.10$ to 0.10$)$ & -3.3 \\
\hline & Did not attend & 178 & $1.26 \pm 0.34$ & $1.13 \pm 0.28 \ddagger \ddagger$ & $-0.13 \rrbracket(-0.16$ to -0.11$)$ & $-10.3^{\star \star}$ & & & \\
\hline \multirow[t]{2}{*}{ LDL (mmol/L) } & Attended & 106 & $3.36 \pm 0.94$ & $2.56 \pm 0.86$ & $-0.80(-0.90$ to -0.70$)$ & $-23.7^{\star \star}$ & $3.39 \pm 1.01$ & $0.03(-0.19$ to 0.26$)$ & 1.0 \\
\hline & Did not attend & 178 & $3.26 \pm 0.97$ & $2.51 \pm 0.85$ & $-0.75 \rrbracket(-0.83$ to -0.66$)$ & $-23.0^{\star \star}$ & & & \\
\hline \multirow[t]{2}{*}{$\mathrm{TG}(\mathrm{mmol} / \mathrm{L})$} & Attended & 106 & $1.41 \pm 0.74$ & $1.22 \pm 0.61$ & $-0.18(-0.29$ to -0.08$)$ & $-13.1^{*}$ & $1.32 \pm 0.64$ & $-0.08(-0.25$ to 0.09$)$ & -5.9 \\
\hline & Did not attend & 178 & $1.63 \pm 0.84 \ddagger$ & $1.47 \pm 0.66 \ddagger \ddagger$ & $-0.16 \rrbracket(-0.25$ to -0.06$)$ & $-9.8^{*}$ & & & \\
\hline \multirow[t]{2}{*}{ FPG (mmol/L) } & Attended & 106 & $5.72 \pm 1.07$ & $5.36 \pm 0.65$ & $-0.37(-0.50$ to -0.23$)$ & $-6.4^{\star *}$ & $5.65 \pm 0.95$ & $-0.07(-0.27$ to 0.13$)$ & -1.3 \\
\hline & Did not attend & 178 & $6.10 \pm 1.86 \ddagger$ & $5.55 \pm 1.10$ & $-0.55 \rrbracket(-0.77$ to -0.33$)$ & $-9.0^{* *}$ & & & \\
\hline
\end{tabular}

\section{${ }^{* *} p<0.001 ;{ }^{*} p<0.05$.}

†\% change from baseline.

fDifference in baseline between those who attended follow-up and those who did not at $p<0.05$ level of significance.

$\S$ Difference at 30 days between those who attended follow-up and those who did not at $p<0.001$ level of significance.

qDifference in amount of change between those who attended follow-up and those who did not at $p>0.05$ level of significance.

††Difference in baseline between those who attended follow-up and those who did not at $p<0.001$ level of significance.

$\ddagger \ddagger D$ ifference at 30 days between those who attended follow-up and those who did not at $p<0.05$ level of significance.

BMI, body mass index; DBP, diastolic blood pressure; FPG, fasting plasma glucose; HDL, high-density lipoprotein; LDL, low-density lipoprotein; SBP, systolic blood pressure;

TC, total cholesterol; TG, triglyceride. 
Table 2 Changes in biometrics at baseline, 30 days and 3-5 years of follow-up for participants by baseline risk levels ( $n=106$ )

\begin{tabular}{|c|c|c|c|c|c|c|c|}
\hline Factor & Risk level & $\mathbf{N}$ & Baseline & 30 days & $\begin{array}{l}\text { Per cent change; mean change } \\
(95 \% \mathrm{Cl})\end{array}$ & $\begin{array}{l}3-5 \text { years of } \\
\text { follow-up }\end{array}$ & $\begin{array}{l}\text { Per cent change; mean change } \\
(95 \% \mathrm{Cl})\end{array}$ \\
\hline \multirow[t]{2}{*}{ BMI $\left(\mathrm{kg} / \mathrm{m}^{2}\right)$} & $\leq 30$ & 62 & $26.75 \pm 2.33$ & $25.58 \pm 2.17$ & $-4.4 ;-1.17(-1.33 \text { to }-1.02)^{\star \star}$ & $27.03 \pm 3.01$ & $1.1 ; 0.28(-0.34$ to 0.90$)$ \\
\hline & $>30$ & 44 & $34.75 \pm 5.44$ & $33.15 \pm 5.20$ & $-4.6 ;-1.60(-1.93 \text { to }-1.27)^{\star *}$ & $33.65 \pm 5.28$ & $-3.2 ;-1.10(-2.04 \text { to }-0.16)^{\star}$ \\
\hline \multirow[t]{2}{*}{$\mathrm{SBP}(\mathrm{mm} \mathrm{Hg})$} & $<130$ & 46 & $119.04 \pm 8.06$ & $117.89 \pm 10.91$ & $-1.0 ;-1.15(-4.82$ to 2.51$)$ & $129.67 \pm 14.23$ & $8.9 ; 10.63(5.38 \text { to } 15.89)^{\star \star}$ \\
\hline & $\geq 130$ & 60 & $138.97 \pm 8.84$ & $126.92 \pm 10.27$ & $-8.7 ;-12.05(-15.14 \text { to }-8.96)^{\star *}$ & $140.53 \pm 13.49$ & $1.1 ; 1.57(-3.04$ to 6.17$)$ \\
\hline \multirow[t]{2}{*}{ DBP (mm Hg) } & $<85$ & 79 & $72.75 \pm 8.25$ & $72.00 \pm 10.39$ & $-1.0 ;-0.75(-3.20$ to 1.70$)$ & $77.58 \pm 11.23$ & $6.6 ; 4.84(2.19 \text { to } 7.48)^{\star \star}$ \\
\hline & $\geq 85$ & 27 & $89.11 \pm 4.12$ & $77.52 \pm 9.77$ & $-13.0 ;-11.59(-16.15 \text { to }-7.03)^{\star \star}$ & $80.78 \pm 12.55$ & $-9.4 ;-8.33(-14.40 \text { to }-2.27)^{*}$ \\
\hline \multirow[t]{2}{*}{$\mathrm{TC}(\mathrm{mmol} / \mathrm{L})$} & $<5.2$ & 48 & $4.41 \pm 0.52$ & $3.60 \pm 0.64$ & $-18.4 ;-0.81(-0.98 \text { to }-0.65)^{\star \star}$ & $4.73 \pm 1.11$ & $7.3 ; 0.32(-0.03 \text { to } 0.68)^{\wedge}$ \\
\hline & $\geq 5.2$ & 58 & $6.12 \pm 0.66$ & $4.94 \pm 0.80$ & $-19.2 ;-1.18(-1.39 \text { to }-0.97)^{\star \star}$ & $5.78 \pm 1.04$ & $-5.5 ;-0.34(-0.66 \text { to }-0.01)^{*}$ \\
\hline \multirow[t]{2}{*}{$\mathrm{HDL}(\mathrm{mmol} / \mathrm{L})$} & $\begin{array}{l}\geq 1.03 \text { (males); } \\
\geq 1.3 \text { (females) }\end{array}$ & 72 & $1.50 \pm 0.27$ & $1.34 \pm 0.25$ & $-10.5 ;-0.16(-0.12$ to -0.20$) * *$ & $1.40 \pm 0.30$ & $-6.7 ;-0.10(-0.05 \text { to }-0.15)^{\star \star}$ \\
\hline & $\begin{array}{l}<1.03 \text { (males) } \\
<1.3 \text { (females) }\end{array}$ & 34 & $1.04 \pm 0.17$ & $1.00 \pm 0.17$ & $-3.4 ;-0.04(-0.08$ to 0.01$)$ & $1.11 \pm 0.31$ & $7.2 ; 0.07(-0.01$ to 0.16$)$ \\
\hline \multirow[t]{2}{*}{ LDL (mmol/L) } & $<2.6$ & 20 & $2.07 \pm 0.50$ & $1.50 \pm 0.40$ & $-27.5 ;-0.57(-0.73 \text { to }-0.41)^{\star \star}$ & $2.59 \pm 0.83$ & $25.2 ; 0.52(0.10 \text { to } 1.04)^{*}$ \\
\hline & $\geq 2.6$ & 86 & $3.66 \pm 0.73$ & $2.81 \pm 0.74$ & $-23.2 ;-0.85(-0.99 \text { to }-0.71)^{\star \star}$ & $3.58 \pm 0.96$ & $-2.2 ;-0.08(-0.32$ to 0.16$)$ \\
\hline \multirow[t]{2}{*}{$\mathrm{TG}(\mathrm{mmol} / \mathrm{L})$} & $<1.7$ & 80 & $1.09 \pm 0.32$ & $1.05 \pm 0.37$ & $-3.5 ;-0.04(-0.11 \text { to } 0.04)^{*}$ & $1.19 \pm 0.56$ & $9.6 ; 0.11(-0.05$ to 0.26$)$ \\
\hline & $\geq 1.7$ & 26 & $2.39 \pm 0.78$ & $1.76 \pm 0.87$ & $-26.5 ;-0.64(-1.08 \text { to }-0.19)^{*}$ & $1.73 \pm 0.72$ & $-27.5 ;-0.66(-1.09 \text { to }-0.23)^{\star}$ \\
\hline \multirow[t]{2}{*}{$\mathrm{FPG}(\mathrm{mmol} / \mathrm{L})$} & $<5.5$ & 66 & $5.17 \pm 0.29$ & $5.06 \pm 0.30$ & $-2.1 ;-0.11\left(-0.21\right.$ to $-0.01_{-}^{*}$ & $5.29 \pm 0.40$ & $2.4 ; 0.13(0.03 \text { to } 0.22)^{\star}$ \\
\hline & $\geq 5.5$ & 40 & $6.64 \pm 1.26$ & $5.85 \pm 0.76$ & $-11.8 ;-0.79(-1.14 \text { to }-0.43)^{\star \star}$ & $6.24 \pm 1.27$ & $-6.0 ;-0.40(-0.89$ to 0.10$)$ \\
\hline
\end{tabular}

${ }^{*} p<0.05 ;{ }^{* *} p<0.001 ; \wedge p<0.1$.

BMI, body mass index; DBP, diastolic blood pressure; FPG, fasting plasma glucose; HDL, high-density lipoprotein; LDL, low-density lipoprotein; SBP, systolic blood pressure;

TC, total cholesterol; TG, triglyceride. 
Table 3 Changes in biometrics at baseline, 30 days and $3-5$ years of follow-up by baseline level among self-reported compliant participants ( $n=71$ )

\begin{tabular}{|c|c|c|c|c|c|c|c|}
\hline Factor & Risk level & $\mathbf{N}$ & Baseline & 30 days & $\begin{array}{l}\text { Per cent change; mean change } \\
(95 \% \mathrm{Cl})\end{array}$ & $\begin{array}{l}3-5 \text { years of } \\
\text { follow-up }\end{array}$ & $\begin{array}{l}\text { Per cent change; mean change } \\
(95 \% \mathrm{Cl})\end{array}$ \\
\hline \multirow[t]{2}{*}{ BMI $\left(\mathrm{kg} / \mathrm{m}^{2}\right)$} & $\leq 30$ & 39 & $26.51 \pm 2.50$ & $25.33 \pm 2.34$ & $-4.5 ;-1.18\left(-1.40\right.$ to $-0.97^{\star *}$ & $26.22 \pm 2.75$ & $-1.1 ;-0.29(-0.92$ to 0.24$)$ \\
\hline & $>30$ & 32 & $34.82 \pm 4.54$ & $33.29 \pm 4.24$ & $-4.4 ;-1.53\left(-1.92\right.$ to $-1.15^{\star *}$ & $33.35 \pm 4.77$ & $-4.2 ;-1.47(-2.67 \text { to }-0.27)^{\star}$ \\
\hline \multirow[t]{2}{*}{$\mathrm{SBP}(\mathrm{mm} \mathrm{Hg})$} & $<130$ & 35 & $119.00 \pm 8.78$ & $116.94 \pm 11.65$ & $-1.7 ;-2.06(-6.58$ to 2.47$)$ & $127.91 \pm 12.91$ & $7.5 ; 8.91$ (3.54 to 14.29$)^{*}$ \\
\hline & $\geq 130$ & 36 & $138.50 \pm 8.39$ & $127.33 \pm 9.09$ & $-8.1 ;-11.17(-14.79 \text { to }-7.55)^{* *}$ & $140.28 \pm 14.83$ & $1.3 ; 1.78(-4.74$ to 8.29$)$ \\
\hline \multirow[t]{2}{*}{$\mathrm{DBP}(\mathrm{mm} \mathrm{Hg})$} & $<85$ & 55 & $72.93 \pm 8.65$ & $71.60 \pm 10.84$ & $-1.8 ;-1.33(-4.31$ to 1.66$)$ & $78.31 \pm 11.61$ & $7.4 ; 5.38(2.53 \text { to } 8.23)^{\star \star}$ \\
\hline & $\geq 85$ & 16 & $88.31 \pm 3.16$ & $76.88 \pm 7.85$ & $-13.0 ;-11.44(-16.94 \text { to }-5.93)^{\star *}$ & $77.13 \pm 12.13$ & $-12.7 ;-11.19(-19.10 \text { to }-3.28)^{*}$ \\
\hline \multirow[t]{2}{*}{$\mathrm{TC}(\mathrm{mmol} / \mathrm{L})$} & $<5.2$ & 31 & $4.34 \pm 0.55$ & $3.61 \pm 0.65$ & $-16.9 ;-0.73(-0.92 \text { to }-0.55)^{\star \star}$ & $4.65 \pm 1.07$ & $7.1 ; 0.31(-0.15$ to 0.76$)$ \\
\hline & $\geq 5.2$ & 40 & $6.10 \pm 0.57$ & $4.95 \pm 0.78$ & $-18.8 ;-1.15(-1.40 \text { to }-0.90)^{\star \star}$ & $5.78 \pm 0.95$ & $-5.3 ;-0.33(-0.69 \text { to } 0.04)^{\wedge}$ \\
\hline \multirow[t]{2}{*}{$\mathrm{HDL}(\mathrm{mmol} / \mathrm{L})$} & $\begin{array}{l}\geq 1.03 \text { (males); } \\
\geq 1.3 \text { (females) }\end{array}$ & 51 & $1.51 \pm 0.26$ & $1.35 \pm 0.23$ & $-10.3 ;-0.16(-0.21 \text { to }-0.10)^{\star \star}$ & $1.40 \pm 0.29$ & $-7.4 ;-0.11(-0.19 \text { to }-0.03)^{\star}$ \\
\hline & $\begin{array}{l}<1.03 \text { (males); } \\
<1.3 \text { (females) }\end{array}$ & 20 & $1.05 \pm 0.16$ & $1.03 \pm 0.18$ & $-2.3 ;-0.02(-0.09$ to 0.05$)$ & $1.06 \pm 0.23$ & $0.5 ; 0.01(-0.09$ to 0.10 \\
\hline \multirow[t]{2}{*}{ LDL (mmol/L) } & $<2.6$ & 15 & $2.03 \pm 0.57$ & $1.45 \pm 0.44$ & $-28.9 ;-0.59(-0.78 \text { to }-0.39)^{\star *}$ & $2.63 \pm 0.95$ & $29.4 ; 0.60(-0.10$ to 1.30$)$ \\
\hline & $\geq 2.6$ & 56 & $3.68 \pm 0.67$ & $2.89 \pm 0.72$ & $-21.6 ;-0.80(-0.96 \text { to }-0.63)^{\star *}$ & $3.59 \pm 0.93$ & $-2.5 ;-0.09(-0.36$ to 0.17$)$ \\
\hline \multirow[t]{2}{*}{$\mathrm{TG}(\mathrm{mmol} / \mathrm{L})$} & $<1.7$ & 52 & $1.03 \pm 0.32$ & $0.99 \pm 0.31$ & $-3.5 ;-0.04(-0.13$ to 0.06$)$ & $1.13 \pm 0.62$ & $10.1 ; 0.10(-0.12$ to 0.32$)$ \\
\hline & $\geq 1.7$ & 19 & $2.33 \pm 0.80$ & $1.69 \pm 0.88$ & $-27.3 ;-0.64(-1.10 \text { to }-0.18)^{*}$ & $1.71 \pm 0.76$ & $-26.8 ;-0.62\left(-1.10\right.$ to $-0.15^{\star}$ \\
\hline \multirow[t]{2}{*}{$\mathrm{FPG}(\mathrm{mmol} / \mathrm{L})$} & $<5.5$ & 48 & $5.15 \pm 0.30$ & $5.06 \pm 0.30$ & $-1.9 ; 0.10(-0.23$ to 0.03$)$ & $5.32 \pm 0.39$ & $3.3 ; 0.17(0.05 \text { to } 0.28)^{\star}$ \\
\hline & $\geq 5.5$ & 23 & $7.04 \pm 1.49$ & $5.96 \pm 0.83$ & $-15.4 ;-1.09(-1.62 \text { to }-0.55)^{\star \star}$ & $6.31 \pm 1.33$ & $-10.4 ;-0.74(-1.36 \text { to }-0.11)^{*}$ \\
\hline
\end{tabular}

${ }^{*} p<0.05 ;{ }^{* *} p<0.001 ; \wedge p<0.1$.

BMI, body mass index; DBP, diastolic blood pressure; FPG, fasting plasma glucose; HDL, high-density lipoprotein; LDL, low-density lipoprotein; SBP, systolic blood pressure;

TC, total cholesterol; TG, triglyceride. 


\section{DISCUSSION}

Substantial reductions in selected chronic disease risk factors were achieved within the 30-day CHIP lifestyle intervention, and importantly, the majority of these reductions were maintained 3 or more years among those participants who returned for follow-up assessment and entered the programme with elevated biometrics. These findings are particularly noteworthy as the intervention was administered by trained volunteers, which is a very cost-effective mode for delivering lifestyle interventions.

Strengths of this study and comparison with other studies The 30-day results observed in this study are comparable to other studies of the CHIP intervention delivered by health professionals as well as trained volunteers in the USA and Australasia. ${ }^{78}{ }^{15}$ Longer term studies of participants in two professionally presented CHIP interventions have separately shown decreases in most biometrics at 6 and 12 months of follow-up. ${ }^{17}{ }^{18}$ However, the present study is the longest term appraisal of the CHIP intervention, and the only study of the sustainability of improvements achieved following participation in volunteer-delivered programmes. The results in this study are similar in magnitude to those observed in a professionally delivered randomised control trial in which the participants entered the programme with much higher levels of BMI, DBP, TC, TG and FPG than the participants in this study. ${ }^{21}$

The results of this study also compare favourably to other professionally delivered lifestyle interventions. ${ }^{22-24}$ One of the goals of the Diabetes Prevention Programme is for a reduction in the body weight of at least $7 \% .{ }^{25}$ Participants in the present study with elevated FPG at programme entry and who reported being compliant to the lifestyle principles presented in the CHIP intervention achieved a $5.2 \%$ reduction in body weight. This is a noteworthy outcome given that many of these participants did not receive ongoing support beyond the 30-day intervention. While ongoing support is recognised as important for minimising health behaviour decay and maintenance of long-term behavioural change, ${ }^{26}{ }^{27}$ these results suggest that even a short-lasting lifestyle intervention can have long-lasting benefits. It is also interesting that attending the postintervention support meetings or participating in the CHIP intervention with a partner was not related to postintervention compliance to the lifestyle principles presented in the programme. Other researchers have found attending an intervention with a spouse or friend provides the greatest long-term weight loss. ${ }^{28} 29$ The outcomes of this study may have been improved if all participants had engaged in ongoing support meetings. Even so, meaningful improvements in chronic disease risk factors can be achieved in some individuals without follow-up support. Strategies, however, for optimising engagement in lifestyle interventions and increasing attendance at support meetings need to be explored further.

\section{Factors contributing to the outcomes}

One of the factors that may have contributed to the sustained outcomes observed in this study is the intensiveness of the intervention. With the intervention comprising 16 group sessions, CHIP is more intensive than most other community-based lifestyle interventions. ${ }^{11} 30{ }^{31}$ Studies of the long-term effectiveness of lifestyle interventions for reducing body weight, lipid levels, diabetes control and even the regression of atherosclerotic plaques, have shown a clear dose response. ${ }^{35} 6{ }^{32}$ However, other interventions in the literature are typically of 3-months duration, which may be more desirable for optimal long-term effects than the 30-day CHIP intervention. ${ }^{33}$ Indeed, there is a need for further research to determine the most efficacious dosages of lifestyle interventions with regard to the number of sessions, programme duration, and the type and magnitude of lifestyle modifications targeted. While cost was not a concern in this study as volunteers delivered the interventions, an understanding of dose response when applying lifestyle interventions will be an important consideration for making professionally delivered programmes cost-effective.

A second factor that may have contributed to the sustained weight loss observed in this study is the unique eating pattern advocated in the CHIP intervention. Most weight loss programmes restrict energy intake by limiting portion sizes or food choices. However, this approach tends to result in hunger and dissatisfaction with the eating regime, which contributes to low compliance and weight regain. ${ }^{34-36}$ Indeed, weight loss is rarely seen beyond 2 years of treatment. ${ }^{36} 37$ The CHIP intervention allows an ad libitum eating pattern that emphasises the consumption of plant-based whole foods, which are high in bulk, and therefore satiating, yet by nature not calorically dense. This ad libitum eating pattern may be more acceptable to the participant than more restrictive diets. In fact, Barnard et $a \hat{l}^{88}$ reported similar levels of acceptability of plant-based diets to more traditional diets such as that recommended by the American Dietetic Association.

Long-term compliance to prescriptive regimes may also be more likely when participants enter a programme with more adverse health parameters. Various studies have shown that patients with established disease are able to maintain high levels of adherence to intensive and prescriptive regimes. ${ }^{3} 563239$ Indeed, adherence to structured regimes has been shown to be more effective for weight loss than focusing on the macronutrient distribution. ${ }^{40}{ }^{41}$ In the present study, more promising outcomes were found among at-risk patients who reported being compliant to the CHIP lifestyle principles and entered the programme with BMI indicative of obesity, and lipid and FPG profiles indicative of metabolic syndrome. Likely, these individuals entered the programme with an elevated 
readiness for change and hence willingness to engage in the intervention. ${ }^{42}$

\section{Limitations of the study}

There are some limitations of this study that may have affected the observed results. First, only $37 \%$ of participants accepted the invitation to attend the long-term follow-up assessment. The results of this analysis are therefore applicable to those participants who attended the long-term assessment and are not generalisable to the original cohort. While this represents a typical response rate for behavioural interventions, ${ }^{43}$ it is possible that the individuals who were more compliant to the lifestyle principles presented in the intervention were more inclined to return for retesting, thereby biasing the outcomes. There were essentially no differences between those who did and did not return for the long-term follow-up assessment in their biometrics at programme entry or the outcomes achieved during the 30-day intervention, so these factors do not appear to account for the difference in response rate. It is likely that some of the 121 participants who did not respond to the invitation could not be contacted as they were no longer residing in the area were not available at the time of retesting, or chose not to respond. Some of those choosing not to return may have done so because they had not been compliant to the CHIP principles. Nevertheless, even if the 71 participants who reported they were compliant comprised all the compliant individuals from the study sample of 284, this would still represent $25 \%$ of the original cohort. Hence, it is encouraging that between $25 \%$ and $70 \%$ of the individuals who participated in the CHIP intervention reported being compliant to the lifestyle principles promoted in the programme on an average of 4 years after the 30-day intervention. Self-reported compliance was a further limitation of the study. As this was a subjective measure, variation in adherence to the CHIP lifestyle principles may have attenuated the long-term outcomes in the compliant group.

Lifestyle behaviours, such as dietary intake and physical activity, were also inadequately measured in the study. Therefore, it was not possible to determine the extent of changes in lifestyle behaviours the participants adopted during, and subsequent to, the 30-day intervention. Longitudinal studies need to collect comprehensive and validated lifestyle measurements and use these consistently throughout the duration of the study. Finally, the study only involved a small sample. Further investigation on a larger cohort is warranted.

\section{Implications for public health and future directions}

The novel finding of this study is that long-term reductions in chronic disease risk factors can be achieved through an intensive, professionally developed lifestyle intervention delivered by volunteers. Harnessing the energy of volunteers to facilitate lifestyle interventions may provide a cost-effective mode for administering lifestyle interventions. A randomised control trial is needed to investigate the effectiveness and sustainability of the lifestyle choices acquired during the CHIP intervention and the associated long-term improvements in chronic disease risk factors. Further, this study needs to be replicated in a larger cohort and in other settings, to ascertain the generalisability of the study results.

\section{Conclusions}

The CHIP intervention can achieve significant reductions in chronic disease risk factors for more than 3 years after programme entry. Further, when delivered by volunteers, the CHIP intervention is an inexpensive tool for addressing the public health crisis of chronic disease that threatens societies, communities, families and individuals. Further study of the long-term effectiveness of the CHIP intervention in other cultural settings is warranted.

Acknowledgements The authors would like to acknowledge the work of Lenora Hurlow, who tirelessly organised the original CHIP interventions and the follow-up study thereby ensuring their smooth administration.

Contributors HD developed the CHIP intervention. TH was involved in the facilitation of the original intervention. All authors were involved in the conception and design of this study. TH and AH sought funding for this study. AH and PR applied for ethics approval. LK conducted the data analyses and LK, DM and PR were involved in interpretation of the analyses. LK and DM drafted the manuscript, and all authors critically revised it for intellectual content. All authors approved the final version to be published. LK is the guarantor.

Funding The study was supported by a grant from the Taranaki Medical Foundation. The study sponsors were not involved in the study design and the collection, analysis and interpretation of data, nor the writing of the article or the decision to submit it for publication. The authors were independent from the study sponsors.

\section{Competing interests None.}

Ethics approval Consent for the study was obtained from New Zealand Health and Disability Upper South B Regional Ethics Committee, ethics reference: URB/11/09/035.

Provenance and peer review Not commissioned; externally peer reviewed.

Data sharing statement No additional data are available.

Open Access This is an Open Access article distributed in accordance with the Creative Commons Attribution Non Commercial (CC BY-NC 3.0) license, which permits others to distribute, remix, adapt, build upon this work noncommercially, and license their derivative works on different terms, provided the original work is properly cited and the use is non-commercial. See: http:// creativecommons.org/licenses/by-nc/3.0/

\section{REFERENCES}

1. World Health Organization. Global status report on noncommunicable diseases 2010. Geneva: World Health Organization, 2011.

2. World Health Organization. The global burden of chronic disease. 2013. http://www.who.int/nutrition/topics/2_background/en/

3. Barnard RJ, Guzy P, Rosenberg J, et al. Effects of an intensive exercise and nutrition program on patients with coronary artery disease: five-year follow-up. J Cardiac Rehabil 1983;3:183-90.

4. Ornish D, Brown SE, Scherwitz LW, et al. Can lifestyle changes reverse coronary heart disease? The lifestyle heart trial. Lancet 1990;336:129-33.

5. Ornish D, Scherwitz LW, Billings $\mathrm{JH}$, et al. Intensive lifestyle changes for reversal of coronary heart disease. JAMA 1998;280:2001-7 
6. Esselstyn CB Jr, Ellis SG, Medendorp SV, et al. A strategy to arrest and reverse coronary artery disease: a 5-year longitudinal study of a single physician's practice. J Fam Pract 1995;41:560-8.

7. Rankin $\mathrm{P}$, Morton DP, Diehl $\mathrm{H}$, et al. Effectiveness of a volunteer-delivered lifestyle modification program for reducing cardiovascular disease risk factors. Am J Cardiol 2012;109:82-6.

8. Morton DP, Rankin P, Morey P, et al. The effectiveness of the Complete Health Improvement Program (CHIP) in Australasia for reducing selected chronic disease risk factors: a feasibility study. N Z Med J 2013;126:43-54.

9. Makris AP, Foster GD. Dietary approaches to the treatment of obesity. Psychiatr Clin North Am 2005;28:117-39, viii-ix.

10. Provencher V, Drapeau V, Tremblay A, et al. Eating behaviours, dietary profile and body composition according to dieting history in men and women of the Quebec Family Study. Br J Nutr 2004;91:997-1004.

11. Knowler WC, Fowler SE, Hamman RF, et al:; Diabetes Prevention Program Research Group. 10-year follow-up of diabetes incidence and weight loss in the Diabetes Prevention Program Outcomes Study. Lancet 2009;374:1677-86.

12. Katula JA, Vitolins MZ, Morgan TM, et al. The Healthy Living Partnerships to Prevent Diabetes study: 2-year outcomes of a randomized controlled trial. Am J Prev Med 2013;44(4 Suppl 4): S324-32.

13. Diehl HA. Coronary risk reduction through intensive community-based lifestyle intervention: the Complete Health Improvement Program (CHIP) experience. Am J Cardiol 1998;82:83T-7T.

14. Englert HS, Diehl HA, Greenlaw RL, et al. The effect of a community-based coronary risk reduction: the Rockford CHIP. Prev Med 2007:44:513-19.

15. Merrill RM, Taylor P, Aldana SG. Coronary Health Improvement Project (CHIP) is associated with improved nutrient intake and decreased depression. Nutrition 2008;24:314-21.

16. Thieszen CL, Merrill RM, Aldana SG, et al. The Coronary Health Improvement Project (CHIP) for lowering weight and improving psychosocial health. Psychol Rep 2011;109:338-52.

17. Merrill RM, Aldana SG. Improving overall health status through the CHIP intervention. Am J Health Behav 2009;33:135-46.

18. Aldana SG, Greenlaw RL, Diehl HA, et al. A video-based lifestyle intervention and changes in coronary risk. Health Educ Res 2008;23:115-24.

19. Alberti KG, Eckel RH, Grundy SM, et al. Harmonizing the metabolic syndrome: a joint interim statement of the International Diabetes Federation Task Force on Epidemiology and Prevention; National Heart, Lung, and Blood Institute; American Heart Association; World Heart Federation; International Atherosclerosis Society; and International Association for the Study of Obesity. Circulation 2009;120:1640-5.

20. National Cholesterol Education Program. Third report of the National Cholesterol Education Program (NCEP) expert panel on detection, evaluation, and treatment of high blood cholesterol in adults (Adult Treatment Panel III) final report. Circulation 2002; 106:3143-421.

21. Aldana SG, Greenlaw RL, Diehl HA, et al. The behavioral and clinical effects of therapeutic lifestyle change on middle-aged adults. Prev Chronic Dis 2006;3:A05.

22. Jenkins DJ, Jones PJ, Lamarche B, et al. Effect of a dietary portfolio of cholesterol-lowering foods given at 2 levels of intensity of dietary advice on serum lipids in hyperlipidemia: a randomized controlled trial. JAMA 2011;306:831-9.

23. Roberts CK, Barnard RJ. Effects of exercise and diet on chronic disease. J Appl Physiol 2005;98:3-30.
24. Barnard RJ. Effects of life-style modification on serum lipids. Arch Intern Med 1991;151:1389-94.

25. Knowler WC, Barrett-Connor E, Fowler SE, et al. Reduction in the incidence of type 2 diabetes with lifestyle intervention or metformin. N Engl J Med 2002;346:393-403.

26. Sacks FM, Bray GA, Carey VJ, et al. Comparison of weight-loss diets with different compositions of fat, protein, and carbohydrates. $N$ Engl J Med 2009;360:859-73.

27. Merrill RM, Aldana SG, Greenlaw RL, et al. Can newly acquired healthy behaviors persist? An analysis of health behavior decay. Prev Chronic Dis 2008;5:A13.

28. McLean N, Griffin S, Toney K, et al. Family involvement in weight control, weight maintenance and weight-loss interventions: a systematic review of randomised trials. Int J Obes Relat Metab Disord 2003;27:987-1005.

29. Wing RR, Jeffery RW. Benefits of recruiting participants with friends and increasing social support for weight loss and maintenance. J Consult Clin Psychol 1999;67:132-8.

30. Howard BV, Van Horn L, Hsia J, et al. Low-fat dietary pattern and risk of cardiovascular disease: the Women's Health Initiative Randomized Controlled Dietary Modification Trial. JAMA 2006;295:655-66.

31. Davis NJ, Tomuta N, Schechter C, et al. Comparative study of the effects of a 1-year dietary intervention of a low-carbohydrate diet versus a low-fat diet on weight and glycemic control in type 2 diabetes. Diabetes Care 2009;32:1147-52.

32. Barnard RJ, Massey MR, Cherny S, et al. Long-term use of a high-complex-carbohydrate, high-fiber, low-fat diet and exercise in the treatment of NIDDM patients. Diabetes Care 1983;6:268-73.

33. Artinian NT, Fletcher GF, Mozaffarian D, et al. Interventions to promote physical activity and dietary lifestyle changes for cardiovascular risk factor reduction in adults: a scientific statement from the American Heart Association. Circulation 2010;122:406-41.

34. Cuntz U, Leibbrand R, Ehrig C, et al. Predictors of post-treatment weight reduction after in-patient behavioral therapy. Int $J$ Obes 2001;25(Suppl 1):S99-101.

35. Elfhag K, Rossner S. Who succeeds in maintaining weight loss? A conceptual review of factors associated with weight loss maintenance and weight regain. Obes Rev 2005;6:67-85.

36. Vogels N, Diepvens K, Westerterp-Plantenga MS. Predictors of long-term weight maintenance. Obes Res 2005;13:2162-8.

37. Wing RR, Phelan S. Long-term weight loss maintenance. Am J Clin Nutr 2005;82:222S-5S.

38. Barnard ND, Gloede L, Cohen J, et al. A low-fat vegan diet elicits greater macronutrient changes, but is comparable in adherence and acceptability, compared with a more conventional diabetes diet among individuals with type 2 diabetes. J Am Diet Assoc 2009;109:263-72.

39. Silberman A, Banthia R, Estay I, et al. The effectiveness and efficacy of an intensive cardiac rehabilitation program in 24 sites. Am $J$ Health Promot 2010;24:260-6.

40. Dansinger ML, Gleason JA, Griffith JL, et al. Comparison of the Atkins, Ornish, weight watchers, and zone diets for weight loss and heart disease risk reduction: a randomized trial. JAMA 2005;293:43-53.

41. Foster GD, Wyatt HR, Hill JO, et al. Weight and metabolic outcomes after 2 years on a low-carbohydrate versus low-fat diet: a randomized trial. Ann Intern Med 2010;153:147-57.

42. Norcross JC, Krebs PM, Prochaska JO. Stages of change. J Clin Psychol 2011:67:143-54

43. Baruch $\mathrm{Y}$, Holtom BC. Survey response rate levels and trends in organizational research. Human Relations 2008;61:1139-60. 